\title{
Effects of bizarre imagery on the long-term retention of paired associates embedded within variable contexts
}

\author{
JAMES F. IACCINO, ELIZABETH DVORAK, and MARY COLER \\ Illinois Benedictine College, Lisle, Illinois
}

(Charles W. Eriksen, Sponsor)

\begin{abstract}
Recent findings have shown that bizarre imagery can be an effective mnemonic aid when lengthy retention intervals are employed (O'Brien \& Wolford, 1982), and when the surrounding context contains more normal elements (McDaniel \& Einstein, 1986). We therefore hypothesized an interaction between context and time of testing with bizarre images. Forty male and female undergraduates were tested in pairs. Each pair was presented with three lists (i.e., normal, bizarre, and mixed), arranged in a randomized order. The sentences within each list consisted of stimulus-response pairs of high-imagery nouns. Each subject pair was told to form an interactive mental image of the two nouns within a restricted period. Then, one subject participated in an immediate cued recall condition for each list while the other was tested after a 1-week retention interval. As predicted, we found a list $x$ test interaction in which items from the mixed list were recalled best under delayed recall. Our results suggest that bizarre images do enhance memory over time, especially when common materials provide a contrasting surround.
\end{abstract}

Experiments designed to demonstrate the advantage of bizarre imagery in recall have produced mixed results. When interaction between the stimulus materials has been controlled for, bizarreness has had no beneficial effect over the more plausible images. In fact, some researchers (Collyer, Jonides, \& Bevan, 1972; Wollen, Weber, \& Lowry, 1972) reported that bizarre images affected retention adversely. More recently, other variables have been examined to further test the mnemonic effectiveness of bizarreness. O'Brien and Wolford (1982), among others (Andreoff \& Yarmey, 1976; Iaccino \& Spirek, 1983; Webber \& Marshall, 1978), found that bizarre images resulted in significantly better memories when delayedrecall intervals were presented. McDaniel and Einstein (1986) further discovered that this effect could be obtained when the stimulus materials contained both normal and bizarre elements (i.e., a mixed-context condition). The latter finding would seem to support the distinctiveness theory posited by Jacoby and Craik (1979) that specifically states that more durable encodings of materials are produced when the surrounding context is dissimilar to these materials. On the basis of this research, we hypothesized an interaction between context and time of testingnamely, that distinctiveness of bizarre images within a normal surround would be enhanced when longer retention intervals (similar to those of O'Brien \& Wolford, 1982) were employed.

Correspondence may be addressed to James F. Iaccino, Department of Sociology/Psychology, Illinois Benedictine College, 5700 College Rd., Lisle, IL 60532-0900.

\section{METHOD}

Subjects

Forty (male and female) Illinois Benedictine College students participated in the study as part of their course requirements for a learningcognition laboratory. The subjects were tested in randomly assigned pairs

\section{Apparatus}

All subjects were presented with the same sets of sentences for each list (i.e., normal, bizarre, and mixed).

As Table 1 shows, each sentence consisted of a stimulus-response pair of high-imagery nouns selected from the Kroll, Schepeler, and Angin (1986) design. Each list contained a total of 20 such arranged sentences, with 10 normal and 10 bizarre statements comprising the mixed list. Lafayette Company's “'Old Reliable” Memory Drum (Model No. 23010) presented the prepared materials at 4-sec intervals, and an electronic stopwatch (Lafayette Model No. 14705XP) assessed imageformation times to approximately $1 / 100$ th of a second.

\section{Procedure}

The following methodology was similar to the Kroll et al. (1986) format. Each subject was informed that for each sentence presented they would have to form an interactive mental image of the two capitalized high-imagery nouns within a 4-sec period. They also were required to rate the vividness of their image on a 5-point scale during this interval, with 1 representing no image present to 5 representing greatest image clarity. Image-formation times for each noun pair were subsequently recorded by the experimenter's stopwatch.

Each pair of subjects received a randomized order of normal, bizarre, and mixed (bizarre-normal) lists. A 3-min distractor task was used between list presentations to reduce interference effects; specifically, the assignment required the subjects to count backwards by threes from a three-digit number, 297. Then, one subject from the pair participated in an immediate-recall condition, whereby he/she received a cued sheet containing the capitalized stimulus terms from each list and was asked to recall the associated response terms within a 10-sec interval. The second subject of the pair was tested after a 1-week retention interval on a similar cued-recall task. The number of correct responses for each pair of subjects was recorded by the experimenter, with synonyms be- 
Table 1

Sentences Presented In the Normal, Bizarre, and Mixed Lists

\section{Normal List}

A REFRIGERATOR stands by a TABLE.

The AIRPLANE flies over the TREE.

The SPOON rests against the CUP.

The MOP is by the PAIL.

The PENCIL is alongside the CALCULATOR.

The POLICEMAN rests against the WALL.

The TROUT swims under the CANOE.

A DOG watches the FRISBEE.

A BASEBALL rolls beneath the WINDOW.

The CARPENTER goes to the SHED.

The MICROPHONE is near the DRUM.

A JACKET is tossed on the BED.

The WAITER wears a NECKTIE.

The COCKROACH runs toward the STOVE.

The COFFEE is by the SPONGE.

The SURFBOARD is near the DOOR.

The QUEEN wears a LOCKET.

The DOCTOR ignores the TELEPHONE.

An ANT goes around a COMB.

The CAT walks toward the FIREPLACE.

\section{Bizarre List}

The GRASS is growing on the girl's FEET.

The BALLERINA is wearing a birthday CAKE.

A FLASHLIGHT plucks the strings of a VIOLIN.

The rushing WATERFALL fills up a BALLOON.

An AUTOMOBILE protects itself with an UMBRELLA.

The BOY is attacked by an American FLAG.

The oil PAINTING is being created by a RABBIT.

A yellow CANARY bends open a HAIRPIN.

The HAY is eating up the large HORSE.

An ENVELOPE is wearing ornate EARRINGS.

The log CABIN is smoking a VOLCANO.

An enormous ELEPHANT is playing a TUBA.

The SANDALS are ringing church BELLS.

CATERPILLARS are gluing together model KITS.

The COCONUTS are buying short-sleeved SHIRTS.

The alarm CLOCK is drinking a bottle of WINE.

The KING is frozen inside a GLACIER.

A BEAVER is putting on a leather VEST.

A SKYSCRAPER is cleaning with a BROOM.

The NEWSPAPER wraps itself around the SOLDIER.

Mixed List

A BICYCLE is ridden by the HOUSE.

The PROFESSOR writes on the CHALKBOARD.

The BUTTERFLY takes off with the COIN.

A BOULDER is picked up by the FROG.

The PINEAPPLE is near the KNIFE.

The COW climbs up the BILLBOARD.

The EGGS are next to the NAPKIN.

The COOKIE is on the COUNTER.

A ROSE wears an elegant TUXEDO.

The STAR shines on the OWL.

The OCEAN rages beneath the TOWER.

A CRATE relaxes in the CHAIR.

The MAGAZINE covers an APPLE.

A BOTTLE plays the PIANO.

The EAGLE lands on the FENCEPOST.

A TULIP washes itself with SHAMPOO.

A FEATHER tickles the PLUMBER.

The KEY lies in the BOX.

The TRAIN is derailed by STRAWBERRIES.

A CANDLE is lit within the CHURCH. ing treated as equally accurate. For the bizarre items especially, the subjects had to describe the unusual interaction with each stimulus term (e.g., strawberries have overturned the train) so that responses to this type of imagery could be properly differentiated from the more normal.

\section{RESULTS}

\section{Vividness and Formation Times}

Consistent with the McDaniel and Einstein (1986) findings, an analysis of the vividness ratings showed that common images $(M=4.20, S D=1.88)$ were more vivid than the bizarre $(M=2.13, S D=1.24)$. Imageformation times, however, did not replicate previous results (Kroll et al., 1986). The subjects apparently took the same amount of time to construct both bizarre and normal types of images, with respective means of 2.76 $(S D=2.12)$ and $2.48(S D=1.90)$. It should be noted that the experimental demand of forming each image at a rapid pace (every $4 \mathrm{sec}$ ) possibly could account for this discrepant finding.

\section{Recall}

A $2 \times 3$ mixed factorial design was further employed to analyze the proportion of response terms correctly recalled, with type of list (normal, bizarre, and mixed) being treated as a within-subjects factor and type of recall (immediate and delayed) a between-subjects factor. Main effects were found for both factors $[F(1,34)=6.92$, $M S e=.86, p<.05$ and $F(1,34)=12.48, M S e=.86$, $p<.01$, respectively]. Moreover, a highly significant list $\times$ recall interaction occurred, confirming our major prediction $[F(1,34)=9.54, M S e=.86, p<.01]$. Specifically, both normal and bizarre items from the mixed list were recalled significantly better than were those from the other lists when recall was tested after one week. Also, Table 2 indicates that delay affected retention adversely, especially with normal list items.

\section{DISCUSSION}

Our results support the distinctiveness theory in that bizarre encodings enhanced memory when common materials were embedded within the learning context, but only with the delayed-recall condition. This effect, however, was quite consistent with O'Brien and Wolford's (1982) view that bizarre images were less susceptible to interfering events over time. We suggest that their intervening retention intervals had enough commonplace situations to produce distinctive (and highly durable) bizarre images. Apparently, mixed materials also contributed to better recall of normal images (as well as bizarre ones) over time than did

Table 2

Mean Number of Response Terms Recalled as a Function of List and Type of Recall

\begin{tabular}{lcc}
\hline & \multicolumn{2}{c}{ Type of Recall } \\
\cline { 2 - 3 } Type of List & Immediate & Delayed \\
\hline Normal & 16.25 & 4.84 \\
Bizarre & 13.78 & 7.23 \\
Mixed & 15.01 & 9.64 \\
\hline
\end{tabular}

Note-Maximum number of correct terms recalled $=20.00$. 
materials in a context without this contrasting surround. Furthermore, these experimental findings are definitely consonant with the highly successful "bizarre situation in everyday setting" formulas employed in the media by such noted writers and producers as Stephen King and Steven Spielberg.

In conclusion, depending on the learning context and the time of recall, bizarre images will either improve recall performance or contribute to its deterioration. Definitely, other variables (e.g., controlled presentation of intervening activities) need to be examined to determine the effects with bizarre imagery. Only then can one generalize these findings to the classroom and other learning environments.

\section{REFERENCES}

ANDREOFF, G. R., \& YARMEY, A. D. (1976). Bizarre imagery associative learning: A confirmation. Perceptual \& Motor Skills, 43, 143-148.

Collyer, S. C., Jonides, J., \& BevaN, W. (1972). Images as memory aids: Is bizarreness helpful? American Journal of Psychology, 85, 31-38.

IACCINo, J. F., \& SPIREK, P. (1983). Retention of plausible versus bizarre mental images as a function of unexpected recall. Paper presented at the Annual Meeting Midwestern Psychological Association, Chicago, Illinois.
JACOBY, L. L., \& Craik, F. I. M. (1979). Effects of elaboration of processing at encoding and retrieval: Trace distinctiveness and recovery of initial context. In L. S. Cermak \& F. I. M. Craik (Eds.), Levels of processing in human memory (pp. 1-21). Hillsdale, NJ: Erlbaum.

Kroll, N. E., Schepeler, E. M., \& ANGin, K. T. (1986). Bizarre imagery: The misremembered mnemonic. Journal of Experimental Psychology: Learning, Memory, \& Cognition, 12, 42-53.

MCDaniel, M. A., \& Einstein, G. O. (1986). Bizarre imagery as an effective memory aid: The importance of distinctiveness. Journal of Experimental Psychology: Learning, Memory, \& Cognition, 12, 54-65. O'BRIEN, E. J., \& WolFORD, C. R. (1982). Effect of delay in testing on retention of plausible versus bizarre mental images. Journal of Experimental Psychology: Learning, Memory, \& Cognition, 8, 148-152.

Webber, S. M., \& MARShall, P. H. (1978). Bizarreness effects in imagery as a function of processing level and delay. Journal of Mental Imagery, 2, 291-30c.

Wollen, K. A., Weber, A., \& Lowry, D. H. (1972). Bizarreness versus interaction of mental images as determinants of learning. Cognitive Psychology, 3, 518-523.

(Manuscript received July 22, 1988.)

\section{Notice}

\section{Annual Meeting of the Psychonomic Society Change in Dates}

The dates of the annual meeting of the Psychonomic Society for 1989 have been changed from Friday-Sunday, November 10-12 to Friday-Sunday, November 17-19.

The corrected schedule for the next four meetings is:

1989-Atlanta, November 17-19

1990-New Orleans, November 16-18

1991-San Francisco, November 22-24

1992-St. Louis, November 13-15 